The Development of a Detailed Chemical Kinetic Mechanism for Diisobutylene and Comparison to Shock Tube Ignition Times

W. Metcalfe, H. J. Curran, J. M. Simmie, W. J. Pitz, C. K. Westbrook

January 25, 2005

2005 Joint Meeting of the U.S. Sections of the Combustion Institute

Philadelphia, PA, United States

March 20, 2005 through March 23, 2005 
This document was prepared as an account of work sponsored by an agency of the United States Government. Neither the United States Government nor the University of California nor any of their employees, makes any warranty, express or implied, or assumes any legal liability or responsibility for the accuracy, completeness, or usefulness of any information, apparatus, product, or process disclosed, or represents that its use would not infringe privately owned rights. Reference herein to any specific commercial product, process, or service by trade name, trademark, manufacturer, or otherwise, does not necessarily constitute or imply its endorsement, recommendation, or favoring by the United States Government or the University of California. The views and opinions of authors expressed herein do not necessarily state or reflect those of the United States Government or the University of California, and shall not be used for advertising or product endorsement purposes. 


\title{
The Development of a Detailed Chemical Kinetic Mechanism for Diisobutylene and Comparison to Shock Tube Ignition Times.
}

\author{
Wayne Metcalfe $^{1}$, Henry J. Curran ${ }^{1}$, J. M. Simmie ${ }^{1}$, William J. Pitz ${ }^{2}$ and Charles K. Westbrook ${ }^{2}$ \\ ${ }^{1}$ National University of Ireland, Galway, Ireland \\ ${ }^{2}$ Lawrence Livermore National Laboratory, Livermore, CA 94551

\section{Introduction}

There is much demand for chemical kinetic models to represent practical fuels such as gasoline, diesel and aviation fuel. These blended fuels contain hundreds of components whose identity and amounts are often unknown. A chemical kinetic mechanism that would represent the oxidation of all these species with accompanying chemical reactions is intractable with current computational capabilities, chemical knowledge and manpower resources. The use of surrogate fuels is an approach to make the development of chemical kinetic mechanisms for practical fuels tractable. A surrogate fuel model consists of a small number of fuel components that can be used to represent the practical fuel and still predict desired characteristics of the practical fuel. These desired fuel characteristics may include ignition behavior, burning velocity, fuel viscosity, fuel vaporization, and fuel emissions (carbon monoxide, hydrocarbons, soot and nitric oxides). Gasoline consists of many different classes of hydrocarbons including n-alkanes, alkenes, iso-alkanes, cycloalkanes, cycloalkenes, and aromatics. One approach is to use a fuel surrogate that has a single component from each class of hydrocarbon in gasoline so that the unique molecular structure of each class is represented. This approach may lead to reliable predictions of many of the combustion properties of the practical fuel. In order to obtain a fuel surrogate mechanism, detailed chemical kinetic mechanisms must be developed for each component in the surrogate. In this study, a detailed chemical kinetic mechanism is developed for diisobutylene, a fuel intended to represent alkenes in practical fuels such as gasoline, diesel, and aviation fuel. The fuel component diisobutylene usually consists of a mixture of two conjugate olefins of iso-octane: 1- or 2-pentene, 2,4,4-trimethyl. Diisobutylene has a similar molecular structure to iso-octane, so that its kinetics offers insight into the effect of including a double bond in the carbon skeletal structure of iso-octane.

There are few previous studies on diisobutylene. Kaiser et al. [1] examined the exhaust emission from a production spark ignition engine with neat diisobutylene and with it mixed with gasoline. They found the exhaust emissions of diisobutylene to be similar to that of iso-octane. They saw a significant increase in the amount of 2-methyl-1,3-butadiene measured in the exhaust of the engine. They also found appreciable amount of propene in the exhaust, but could not explain the source of this product as they did others in terms of C-C bond beta scission of alkyl radicals. Risberg et al. [2] studied a number of fuel blends to evaluate their autoignition quality for use in a homogeneous charge compression ignition engine, using diisobutylene to represent olefins in one of their test fuels.

In this study, experiments on the shock tube ignition of both isomers of diisobutylene will be described. Then, the development of a detailed chemical kinetic mechanism for the two isomers of diisobutylene will be discussed. Finally, the mechanism will be applied to the shock tube ignition of diisobutylene.

Experimental

All shock tube measurements presented in this paper were obtained in a helium-driven shock tube recently built and characterized at the National University of Ireland, Galway [3]. The experimental apparatus consists of a shock tube, gas handling facility, and light emission diagnostic.

Apparatus

The stainless steel shock tube consists of a $53 \mathrm{~cm}$ long, $52 \mathrm{~cm}$ outer diameter driver section, terminated at one end with a $10 \mathrm{~cm}$ long, $10.24 \mathrm{~cm}$ internal diameter tube, which is separated from the $6 \mathrm{~m}$ long, 10.24 $\mathrm{cm}$ internal diameter test section by a diaphragm. Shock waves were generated by allowing the polycarbonate diaphragm (Makrofol $\mathrm{DE}$, Coloprint $\mathrm{GmbH}$ ) to burst under pressure alone, but with the aid of a cross-shaped cutter to ensure uniform petalling of the diaphragm. A series of four pressure transducers (PCB 113A21) mounted flush with the internal wall, and located at precise distances from the end-wall were used to measure the incident shock velocity using four universal time counters (Fluke/Phillips PM6666). In order to allow for shock attenuation, the shock velocity at the end-wall was calculated by linearly extrapolating the incident shock velocity to the end-wall.

The emission of $\mathrm{CH}^{*}$ behind the reflected shock wave was monitored using an end-on detection diagnostic [4], consisting of a photodiode array detector (Thorlabs Inc., model PDA55), located directly 
behind a $431 \mathrm{~nm}$ narrow band-pass filter with a spectral bandwidth of $10 \mathrm{~nm}$. Both the filter and the PDA are aligned behind a $6 \mathrm{~mm}$ outer diameter fused silica window embedded in the end-wall. Reflected shock conditions were calculated from shock velocities using the one-dimensional shock relations [5] and the application GASEQ [6].

Mixture Preparation

Test mixtures were prepared in a $35 \mathrm{~L}$ stainless steel tank using standard manometric methods. Gases were obtained from BOC Ireland Ltd.: Argon Zero Grade 99.998\%, and Oxygen Research Grade 99.985\%. All gases were used without further purification. The diisobutylene used was obtained from Aldrich Chemical Co. Ltd. and was determined by gas chromatographic analysis to be $99.6 \%$ pure. To minimize the presence of atmospheric air in the sample the liquid diisobutylene was subjected to several freezepump-thaw degassing cycles before being used. Due to saturation and adsorption effects the fuel partial pressure was kept significantly below the room temperature saturation vapor pressure. The liquid diisobutylene was incorporated into the mixing vessel by vaporization of the fuel into the evacuated $\left(10^{-6}\right.$ torr) mixing tank. Both fuel and oxygen partial pressures were measured using a 100 torr Baratron gauge to an accuracy of 0.01 torr. For reactant gas pressures above 100 torr, a Wallace and Tiernan 800 torr absolute pressure gauge was used. Test gas mixtures were normally made up to a final pressure of 800 torr. To ensure homogeneity, the mixtures were allowed to stand for 24 hours or mixed for two hours using a magnetic stirring bar. From the resulting mix, initial pressures, $\left(\mathrm{P}_{1}\right)$, varying from 20 to 100 torr were used during these experiments.

Prior to an experiment both the driver and driven sections of the shock tube were evacuated independently. The driver section was evacuated to $10^{-3}$ torr using an Edwards's oil rotary pump, while the driven section was firstly pumped to $10^{-3}$ torr using an Edwards's oil rotary pump, and the final pressure of $10^{-6}$ torr was achieved using an Edwards's oil diffusion pump. The range of experimental data generated for 2,4,4-trimethyl-1-pentene is provided in Table 1.

Ignition Delays

All ignition delay times, $\tau$, for the current study were measured behind the reflected shock, with $\tau$ defined as the time interval from shock arrival at the end-wall, as indicated by an in-situ pressure transducer (Kistler $601 \mathrm{H}$ ), to the maximum in the rate of change of emission with time of light from $\mathrm{CH}^{*}$ at $431 \mathrm{~nm}$. This definition is taken from that of Gutman et al. [4] where a similar end-wall diagnostic was used to measure the emission of light from the reaction $\mathrm{CO}+\mathrm{O} \rightarrow \mathrm{CO}_{2}+\mathrm{h} v$. Their work determined that the initial rise of the emission signal at the end-wall is largely due to the induction period where there is a build-up of the gas behind the reflected shock wave. However, at longer times ( $\tau>35 \mu \mathrm{s})$ the exponential growth of the emission signal was due to the reaction of the test mixture at the end-wall. These findings suggest the ignition onset, measured at the end-wall, should be based on the exponential rise of the $\mathrm{CH}^{*}$ emission trace, and not the initial rise of this signal.

Chemical Kinetic Model

The chemical kinetic model for diisobutylene was constructed based on the iso-octane mechanism of Curran et al. [7]. (The current version of the iso-octane mechanism is available at the LLNL mechanism website [8].) Species and reactions were added to the iso-octane mechanism to treat the oxidation of both isomers of diisobutylene (DIB). (DIB will be used as shorthand below to refer to both isomers.) The diisobutylene isomers were already present in the iso-octane mechanism, so that some reactions and species were already included. There are several different types of reactions that were added. Examples of these types of reactions and the source of their rate constants are discussed below. Initiation reactions

Molecular elimination reactions for DIB were added using the rate constant of Tsang [9]. These reactions are also called retroene reactions [10]. A retroene reaction is only possible from the 1-pentene isomer $\left(\mathrm{jC}_{8} \mathrm{H}_{16}\right): \mathrm{jC}_{8} \mathrm{H}_{16}=>\mathrm{iC}_{4} \mathrm{H}_{8}+\mathrm{iC}_{4} \mathrm{H}_{8}$ where $\mathrm{iC}_{4} \mathrm{H}_{8}$ is iso-butene. No six-membered elimination is possible for the 2-pentene isomer $\left(\mathrm{iC}_{8} \mathrm{H}_{18}\right)$. The retroene reaction was not found to play a role in the shock tube ignition of DIB.

Both C-C and C-H bond breaking reactions were included for the parent fuel. The rate constants were specified by their reverse rate constants with the forward decomposition rate constants being computed from microscopic reversibility. The $\mathrm{C}-\mathrm{H}$ bond breaking reaction rates are slow, but were included because they were important in the reverse direction under shock tube conditions. Reaction of DIB with $\mathrm{O}_{2}$ was also included, but it is not important under shock tube conditions. Under shock tube conditions, the decomposition of the 1-pentene isomer was much faster than the 2-pentene isomer of $\mathrm{C}_{8} \mathrm{H}_{16}$. The same rate constant for $\mathrm{C}-\mathrm{C}$ bond breakage was assumed in the reverse direction for both isomers by analogy with 
the allyl + methyl radical combination reaction. However, in the forward decomposition direction, the preexponential factor computed from microscopic reversibility for the 1-pentene-isomer decomposition was much faster than the 2-pentene isomer.

Abstraction reactions

Abstraction of $\mathrm{H}$ atoms from both alkylic and allylic $\mathrm{C}-\mathrm{H}$ bonds in DIB was included in the mechanism. The abstraction from vinylic $\mathrm{C}-\mathrm{H}$ bonds was neglected because the rate constants are much lower than that of allylic or alkyl C-H [11]. Abstraction by $\mathrm{OH}, \mathrm{H}, \mathrm{CH}_{3}, \mathrm{HO}_{2}, \mathrm{CH}_{3} \mathrm{O}_{2}, \mathrm{CH}_{3} \mathrm{O}, \mathrm{C}_{2} \mathrm{H}_{5}$, and $\mathrm{C}_{2} \mathrm{H}_{3}$ radicals were considered. For $\mathrm{OH}, \mathrm{H}, \mathrm{CH}_{3}+\mathrm{DIB}$, the rate constant parameters for the abstraction of primary alkyl C-H were taken from Curran et al. [7]. The rate constants for the abstraction of primary and secondary allylic C-H bonds were taken from Heyberger et al. [11]. For $\mathrm{HO}_{2}+\mathrm{DIB}$, rate constants were taken from Scott and Walker [12] for allylic and alkyl of C-H bonds. The rate constants for $\mathrm{CH}_{3} \mathrm{O}_{2}+\mathrm{DIB}$ were assumed to be the same as $\mathrm{HO}_{2}+$ DIB. The rate constants for $\mathrm{CH}_{3} \mathrm{O}$ and $\mathrm{C}_{2} \mathrm{H}_{3}+\mathrm{DIB}$ for the abstraction of allylic $\mathrm{C}-\mathrm{H}$ are not available in the literature and were estimated.

Decomposition of DIB radicals $\left(\mathrm{C}_{8} \underline{H_{15}}\right)$

The rate constants for the decomposition of DIB radicals were specified in the reverse exothermic direction. In this direction, the reaction is the addition of a radical to a double bond. The rate constants were taken from Curran [13].

Results and Discussion

First we will discuss the results for 2,4,4-trimethyl-1-pentene. The experimental and computational results show how the ignition delay times are influenced by fuel concentration, oxygen concentration, and pressure. The influence of fuel concentration is seen in Fig. 1 where the ignition delay times increase with increasing fuel concentration. The reason for this behavior is that the fuel reacts with $\mathrm{H}$ atoms that would otherwise react with oxygen and provide chain branching through $\mathrm{H}+\mathrm{O}_{2}=\mathrm{OH}+\mathrm{O}$. The effect of fuel concentration on ignition delay diminishes as the temperature is lowered (Fig. 1) until the effect is reversed for most hydrocarbon fuels at low temperatures [14]. Qualitatively, the trends with fuel concentration are similar in both the experimental and modeling results. Quantitatively, the mechanism predicts ignition delay times that are approximately $50 \%$ faster than those measured experimentally. The magnitude of the decrease in ignition delay time with a decrease in fuel concentration (from $0.75 \%$ to $0.375 \%$ ) is well reproduced by the model.

The influence of oxygen concentration is seen in Fig. 2. The ignition delay time decreases as the oxygen concentration increases from $9 \%$ (squares) to $18 \%$ (circles). This behavior is commonly seen for hydrocarbons where ignition delay time has a negative exponent for its dependence on oxygen concentration [15] [16]. The effect of fuel concentration is also seen in Fig. 2. The fuel concentration is decreased from the data series shown as circles $(0.75 \%$ fuel $)$ to that shown as triangles $(0.375 \%$ fuel $)$. Again, this behavior is similar to other hydrocarbons, which show a slight positive exponent for the dependence of ignition delay time on fuel concentration. Figure 2 shows that the effect of a factor of two change in oxygen concentration has a much more pronounced effect on ignition delay times than a factor of two change in fuel concentration. The modeling results show the same trends as the experiments, except that the modeling curves are shifted toward smaller ignition delay times by about $50 \%$.

The influence of pressure is seen in Fig. 3 where increasing pressure decreases the ignition delay time. The relative shift toward decreased ignition delay times with increasing pressure is well reproduced by the model. Again, the predicted ignition delay times are about $50 \%$ shorter than experimentally measured.

Finally, the effect of fuel composition is considered, examining both isomers and their mixtures (Fig. 4). The experiments show that 2,4,4-trimethyl-2-pentene (squares) is considerably faster to ignite than 2,4,4-trimethyl-1-pentene (triangles). In addition, the mixture that contains three parts 2,4,4-trimethyl-1pentene to one part 2,4,4-trimethyl-2-pentene is intermediate to the pure components. Ignition delay times appear to be directly proportional to the quantity of each isomer present.

The comparative trends in the model results as the fuel is changed from 2,4,4-trimethyl-1-pentene to 2,4,4-trimethyl-2-pentene and to the mixture are quite different than the experiment results (Fig. 4). Further analysis of the experimental results and possible refinements in the kinetic model are needed to explain these differences.

Conclusions

Ignition delay times for 2,4,4-trimethyl-1-pentene have been measured behind reflected shock waves at $4 \mathrm{~atm}$ and at equivalence ratios of $0.25,0.5$, and 1.0. Experiments performed at 1.0 and $4.0 \mathrm{~atm}$ at an equivalence ratio of 1.0 show the influence of pressure. In addition, the reactivity of pure 2,4,4-trimethyl1-pentene, 2,4,4-trimethyl-2-pentene, and a 0.75 2,4,4-trimethyl-1-pentene / 0.25 2,4,4-trimethyl-2-pentene 
Mixture was examined. It was found that of the two isomers, 2,4,4-trimethyl-2-pentene is significantly faster to ignite throughout the temperature range $(1200-1550 \mathrm{~K})$ of this study. The chemical kinetic mechanism developed to interpret these experiments reproduces many of these effects, but continued mechanism development and refinement is being pursued.

Acknowledgments

The work at Lawrence Livermore National Laboratory was supported by the U.S. Department of Energy, Office of Freedom CAR and Vehicle Technologies and under the auspices of the U.S. Department of Energy by University of California, Lawrence Livermore National Laboratory under contract No. W7405-Eng-48. The authors thank program managers Stephen Goguen and Gurpreet Singh for their support of this work. The work at the National University of Ireland, Galway was supported by Science Foundation Ireland under the National Development Plan.

References

1. Kaiser, E. W., Slegl, W., Cotton, D. F. and Anderson, R. W., Environ. Sci, Technol. 27:1440-1447 (1993).

2. Risberg, P., Kalghatgi, G. and Angstrom, H.-E., Auto-ignition Quality of Gasoline-Like Fuels in HCCI Engines, Society of Automotive Engineers, SAE Paper 2003-01-3215, (2003).

3. Smith, J. M., Ph. D. "Construction, Characterisation and Validation of a Shock Tube Facility:

Spectroscopic and Kinetic Studies at High Temperatures", PhD Thesis, National University of Ireland, Galway, 2004.

4. Gutman, D., Hardwidge, E. A., Dougherty, F. A. and Lutz, R. W., J. Chem. Phys. 47:4400-4407 (1967).

5. Gaydon, A. G. and Hurle, I. R., The Shock Tube in High-Temperature Chemical Physics, Chapman and

Hall, London, (1963).

6. Morley, C. GASEQ, http://www.c.morley.ukgateway.net/gseqrite.html, 2005.

7. Curran, H. J., Gaffuri, P., Pitz, W. J. and Westbrook, C. K., Combust. Flame 129:253-280 (2002).

8. Pitz, W. J., Westbrook, C. K. and Curran, H. J. LLNL Chemical Kinetic Mechanisms, 2004.

9. Tsang, W., Int. J. Chem. Kinet. 10:1119-1138 (1978).

10. Richard, C., Scacchi, G. and Back, M. H., Int. J. Chem. Kinet. 10:307-324 (1978).

11. Heyberger, B., Belmekki, N., Conraud, V., Glaude, P.-A., Fournet, R. and Battin-Leclerc, F., Int. J. Chem. Kinet. 34(12):666-677 (2002).

12. Scott, M. and Walker, R. W., Combust. Flame 129(4):365-377 (2002).

13. Curran, H. J., Int. J. Chem. Kinet., submitted (2005).

14. Ciezki, H. K. and Admeit, G., Combust. Flame 93:421-433 (1993).

15. Burcat, A., Scheller, K. and Lifshitz, A., Combust. Flame 16:29-33 (1971).

16. Davidson, D. F. and Hanson, R. K., Int. J. Chem. Kinet. 36(9):510-523 (2004).

\begin{tabular}{|c|c|c|c|}
\hline $\begin{array}{c}\text { 2,4,4-trimethyl- } \\
\text { 1-pentene }\end{array}$ & $\mathrm{O}_{2}$ & $\begin{array}{c}\mathrm{P}_{5} \\
(\mathrm{~atm})\end{array}$ & $(\phi)$ \\
\hline $0.75 \%$ & $9.0 \%$ & 1.0 & 1.0 \\
\hline $0.375 \%$ & $9.0 \%$ & 1.0 & 0.5 \\
\hline $0.75 \%$ & $9.0 \%$ & 4.0 & 1.0 \\
\hline $0.75 \%$ & $18.0 \%$ & 4.0 & 0.5 \\
\hline $0.375 \%$ & $18.0 \%$ & 4.0 & 0.25 \\
\hline
\end{tabular}

Table 1: Experimental conditions examined for 2,4,4-trimethyl-1-pentene oxidation behind reflected shock waves (Percentages are percent mole fractions in reactants. The balance is argon). 


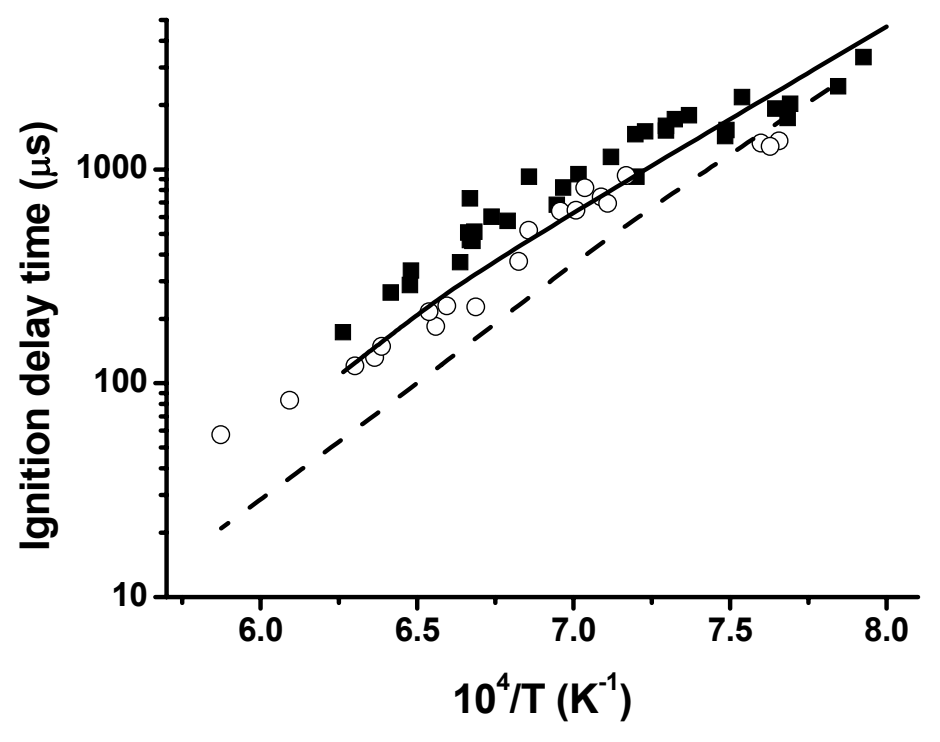

Fig. 1: Experimental (points) and model-predicted (lines) ignition delay times for 2,4,4-trimethyl-1-pentene oxidation behind reflected shock waves at $\mathrm{P}_{5}=1.0 \mathrm{~atm}$ in Ar diluent, $0.75 \%$ fuel $, \phi=1.0, \circ 0.375 \%$ fuel, $\phi=0.5$. Dashed line corresponds to open symbols.

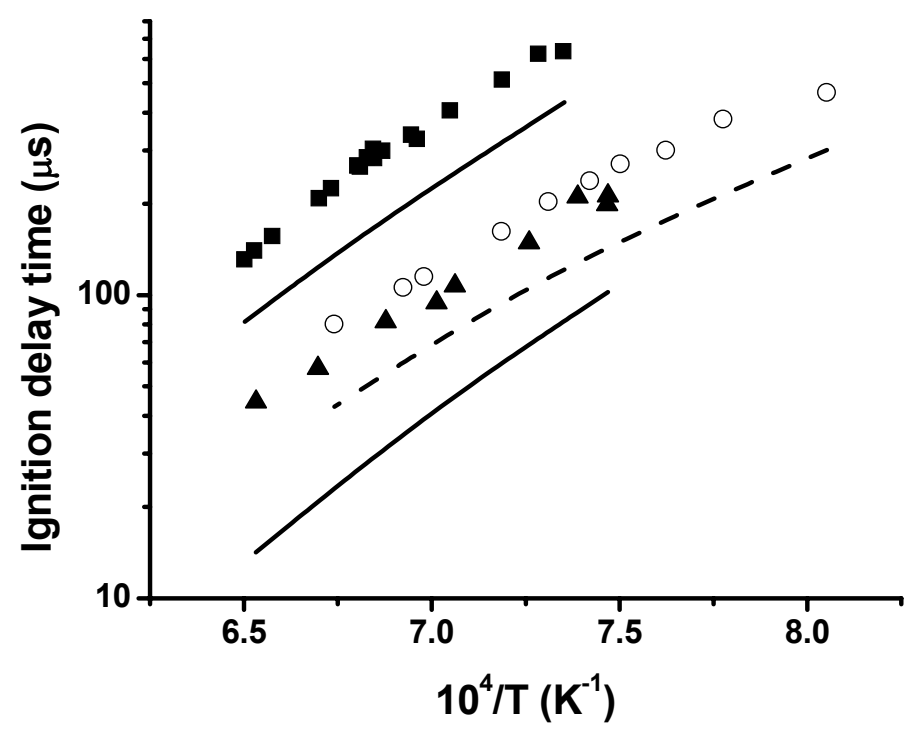

Fig. 2: Experimental (points) and model-predicted (lines) ignition delay times for 2,4,4-trimethyl-1-pentene oxidation behind reflected shock waves at $\mathrm{P}_{5}=4.0 \mathrm{~atm}$ in Ar diluent, $0.75 \%$ fuel, $9.0 \%$ oxygen, $\phi=1.0$, $\circ 0.75 \%$ fuel, $18.0 \%$ oxygen, $\phi=0.5, \boldsymbol{\Delta} 0.375 \%$ fuel, $18.0 \%$ oxygen, $\phi=0.25$. Dashed line corresponds to open symbols. 


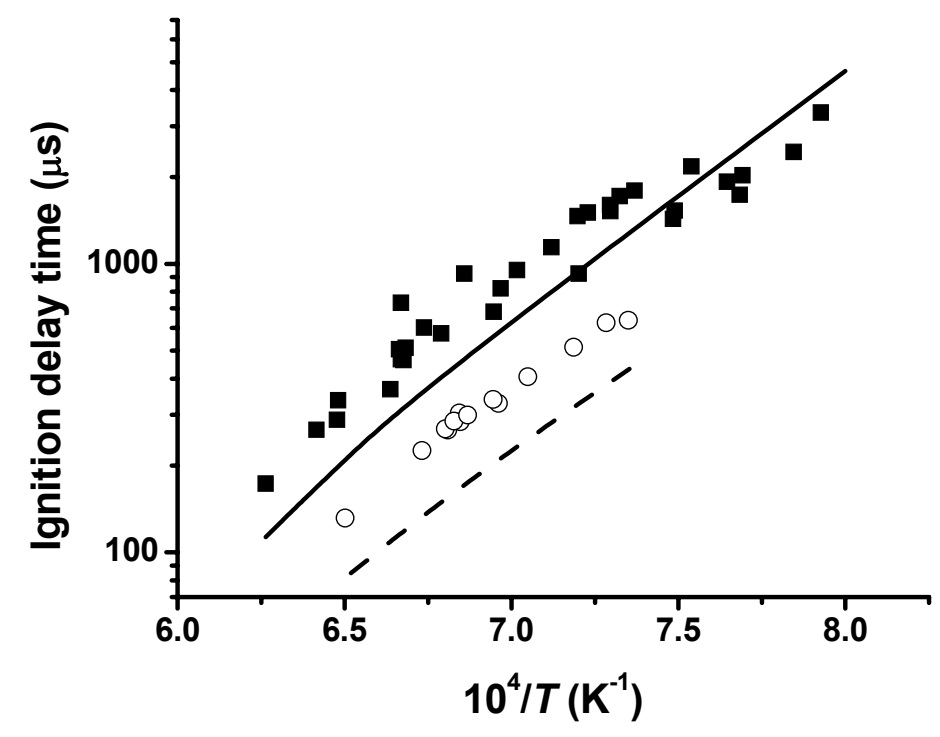

Fig. 3: Experimental (points) and model-predicted (lines) ignition delay times for 2,4,4-trimethyl-1-pentene oxidation behind reflected shock waves at $0.75 \%$ fuel, $\phi=1.0 \mathrm{in}$ Ar diluent, $-\mathrm{P}_{5}=1.0 \mathrm{~atm}, \circ \mathrm{P}_{5}=4.0$ $\mathrm{atm}$. Dashed line corresponds to open symbols

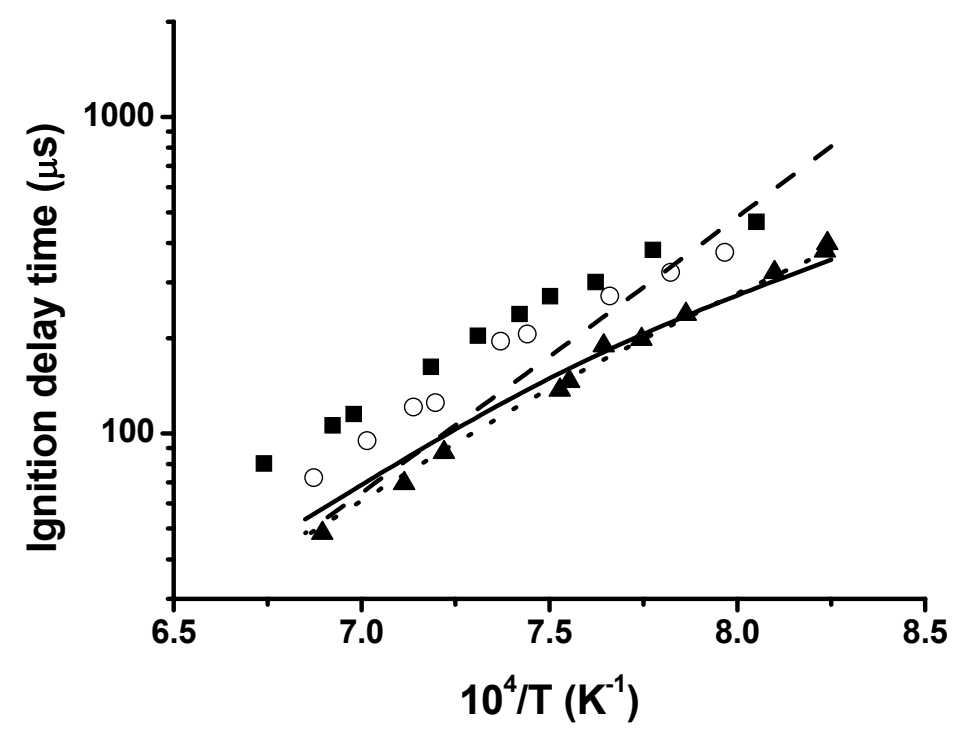

Fig. 4: Experimental (points) and model predicted (lines) ignition delay times for $0.75 \%$ fuel oxidation behind reflected shock waves at $\phi=0.5, \mathrm{P}_{5}=4.0 \mathrm{~atm}$ in Ar diluent, - -

2,4,4-trimethyl-1-pentene, $\circ \cdots \cdots$ 2,4,4-trimethyl-1-pentene : 2,4,4-trimethyl-2-pentene (3:1), $\mathbf{\Delta}$ - - - 2,4,4trimethyl-2-pentene. 